\title{
INFORMAÇÃO GEOGRÁFICA VOLUNTÁRIA NO PROCESSO DE REAMBULAÇÃO
}

\section{Volunteer Geographic information for field survey to collect place names}

\author{
Odair Gonçalves Martins Junior ${ }^{1}$ \\ Julia Celia Mercedes Strauch ${ }^{1,2}$ \\ Cláudio João Barreto do Santos ${ }^{1}$ \\ Rogério Luís Ribeiro Borba ${ }^{3,4}$ \\ Jano Moreira de Souza ${ }^{3}$
}

${ }^{1}$ Universidade do Estado do Rio de Janeiro (UERJ) - Faculdade de Engenharia - Departamento de Engenharia Cartográfica, Rua São Francisco Xavier, n. 524, Bloco B, Maracanã, CEP 20550-900, Rio de Janeiro - RJ, Brasil. E-mail: ogmjcarto@gmail.com, cljclj6@gmail.com

${ }^{2}$ Escola Nacional de Ciências Estatísticas (ENCE/IBGE) - Programa de Pós-graduação Stricto Sensu em População, Território e Estatísticas Públicas, Rua André Cavalcanti, n. 106, sala 503 B, Centro, CEP 20231-050, Rio de Janeiro - RJ, Brasil. E-mail: julia.strauch@ibge.gov.br

3 Universidade Federal do Rio de Janeiro (UFRJ) - Instituto Luís Alberto de Coimbra de Pós-Graduação e Pesquisa em Engenharia - Programa de Engenharia de Sistemas e Computação, Caixa Postal 68.511, CEP: 21945-970, Rio de Janeiro - RJ, Brasil. E-mail: rogerio.borba17@gmail.com, jano@cos.ufrj.br.

${ }^{4}$ Diretoria de Geociências - Instituto Brasileiro de Geografia e Estatística (DGC/IBGE), Av. Brasil, 15671, Parada de Lucas, CEP 21241-05, Rio de Janeiro - RJ, Brasil.

\section{Resumo:}

Este trabalho apresenta uma metodologia para a construção de uma base de dados voluntária em um estudo de caso para coletar dados de postos de combustível no município do Rio de Janeiro e do seu entorno de modo a inserir na base de dados do OpenStreetMap. A partir dessa experiência apresenta uma reflexão sobre a inserção do mapeamento colaborativo no processo de reambulação das Agências Nacionais de Mapeamento de modo a promover uma atualização dinâmica das bases cartográficas e maior participação social nos processos de construção do território.

Palavras-chave: Mapeamento Colaborativo, Reambulação, Mapeamento Oficial.

\begin{abstract}
:
This paper presents a methodology for the construction of a voluntary database using mobile platforms and presents the results in a case study to collect data from gas stations in Rio de Janeiro city and its surroundings in order to insert at the OpenStreetMap database. From this experience presents a reflection about the insertion of collaborative mapping in the field survey process to collect places names of the National Agencies of Mapping in way to promote a
\end{abstract}


dynamic update of cartographic databases and increased social participation in the processes the knowledge of the territory.

Keywords: Collaborative Mapping, Field Survey, National Mapping.

\section{Introdução}

A popularização dos sistemas móveis na sociedade contemporânea tem possibilitado diversas iniciativas que exploram o potencial que os usuários destes sistemas têm em se transformar em verdadeiros sensores inteligentes (Goodchild, 2007) para coletar informações geoespaciais. Na literatura e na Web 2.0 são encontradas diversas dessas iniciativas envolvendo crowdsourcing e especialmente em algumas áreas, como epidemiologia, turismo e meio ambiente (Bearden, 2007; Budhathoki et al., 2008; Heipke, 2010; Dobson, 2013; Mooney e Morley, 2014; GFDRR, 2014).

Um caso de sucesso é OpenStreetMap, que por definição é um mapa gratuito e editável do mundo, que está em permanente construção de modo voluntário e disponibilizado sob uma licença aberta (Haklay e Weber, 2008). Haklay (2010) destaca que a parte mais expressiva desse projeto é a rapidez de coleta e integração dos dados à base. Em um curto espaço de tempo, um terço do território da Inglaterra foi mapeado por uma equipe de 150 participantes auxiliados pontualmente por outros 1000. Após a integração da base de imagens de alta resolução do Yahoo, o processo foi refinado, chegando aos atuais $6 \mathrm{~m}$ de acurácia média e quase $100 \%$ de mapeamento da infraestrutura de transporte em diversas partes do mundo, incluindo o Reino Unido, a Alemanha, a França, os Estados Unidos, o Canadá, o Japão e todas as capitais estaduais do Brasil e o Distrito Federal.

O processo de produção cartográfico foi desenvolvido ao longo da história das Agências Nacionais de Mapeamento no paradigma top-down e centrista onde os profissionais especialistas produziam e disseminavam dados geoespaciais que eram consumidos pelos usuários de acordo com as suas demandas (Goodchild 2007). Atualmente, em países desenvolvidos o mapeamento é uma atividade que investe em novas tecnologias visando estabelecer melhorias nos processos cartográficos para representar o território como, por exemplo, investindo em metodologias para melhorar a qualidade da informação geográfica voluntária (Anand et al., 2010; Haklay e Weber, 2008; Haklay, 2010; Girres e Touya, 2010), bem como oferecer novos produtos on line. Em países em desenvolvimento, o mapeamento é ainda uma atividade de alto custo e trabalhosa, entretanto relevante para o desenvolvimento. Por exemplo, no Brasil, o mapeamento em pequenas escalas encontra-se muitas vezes desatualizados e em escalas maiores que 1:100.000 apresenta-se com vazios cartográficos (Camboim et al., 2008), apesar dos esforços existentes para melhorar os níveis de detalhamento dos mapas existentes.

Atualmente, encontrar uma forma para adquirir o dado geospacial de modo econômico e confiável é um desafio. A demanda contínua de atualização do território e o alto custo dessa atividade podem abrir caminhos para um maior aproveitamento das experiências colaborativas e para o desenvolvimento de outras, estas com maior integração Estado-Sociedade. Entretanto essa integração ainda é um ponto sensível. Um estudo realizado feito pelo centro C2C (Citizen to Citizen) concluiu que os cidadãos interagem com outros cidadãos de forma mais intensa quando comparados com interações com o Estado, que chegam por vezes a evitar (Coleman et al., 2009). 
No Brasil, uma etapa do processo de mapeamento cartográfico que poderia experimentar e se beneficiar do uso dessa tecnologia para aquisição de informação geoespacial é o processo de reambulação. Segundo Santos (2008) a reambulação consiste no:

"ato de percorrer determinada porção territorial com o objetivo de coletar, confirmar ou destacar, a partir de entrevistas com a população que lá habita, o nome das feições cartográficas mais destacadas no local, as quais posteriormente constarão, ou serão descartadas, das cartas e mapas, como nomes geográficos que as identifiquem de forma singular."

O processo de reambulação objetiva capturar os nomes geográficos das feições a serem cartografadas, compreendendo as representações de relevo e outros fenômenos naturais, incluindo estruturas puramente antrópicas. Esse processo está intimamente ligado à história do lugar, desde as suas primeiras ocupações até as sociedades. Muito da memória local está descrita nos nomes que a compõem e os habitantes são a principal fonte destas informações (Santos, 2008). Uma questão relevante neste processo é a regionalidade das informações. O Brasil possui mais de 8,5 milhões de $\mathrm{km}^{2}$, divididos em 26 estados e um distrito federal, com diferentes processos de formação do território, muitas vezes com auxílio de indivíduos de outras culturas e nacionalidades. Essa integração produziu uma riqueza linguística e humana que é um fator essencial na identidade nacional e, portanto, deve ser incluído nos mapas nacionais. Por exemplo, ao tratar a denominação dos nomes genéricos de cursos d'água no Brasil, depara-se com diversas formas regionais para esta feição do território, a saber: Arroio, Água, Aguinha, Braço, Córgão, Corguinho, Corixão, Corixinho, Corixo, Córregão, Córrego, Corregozinho, Esgotinho, Esgoto, Igarapé, Igarapezinho, Ipixuna, Lajeado, Lajeadinho, Lajeadão, Riacho, Riachinho, Riachão, Ribeirão, Ribeirãozinho, Riozinho, Sanga, Valão, Vazante, Vazantinha.

Do ponto de vista jurídico, a reambulação tem uma importância singular no que se refere à atribuição judicial que a informação cartográfica possa vir a ter. Caso um nome de um elemento geográfico não esteja presente ou não esteja correto nos documentos cartográficos oficiais, consequências jurídicas podem ser imputadas a essa informação. Como exemplo, o caso, em 2012, da Lagoa da Turfeira (visitar http://jornalbeirario.com.br/portal/wpcontent/uploads/2014/04/ TAC-NISSAN.pdf e http://scienceblogs.com.br/caapora/2012/04/ainvisivel-lagoa-da-turfeira-uma-tragedia-ambiental-anunciada/), localizada às margens do rio Paraíba do Sul, que não estava identificada nas cartas antigas da Fundação Instituto Brasileiro de Geografia e Estatística (IBGE), foi adquirida pela Nissan para construção da fábrica de veículos e realizada obras de terraplanagem que comprometeram um abrigo da avifauna endêmica e ou migratória, com 160 espécies de pássaros catalogados, alguns em risco de extinção, no município de Resende.

De importância ímpar, no âmbito do processo da produção cartográfica brasileira, a reambulação é a única etapa da produção em que não houve mudanças, nem mesmo integração das tecnologias de informação recentes. Em uma breve revisão na literatura verifica-se que várias etapas do processo de mapeamento das Agências Nacionais de Mapeamento foram modificadas nos últimos 30 anos pela tecnologia de informação e comunicação. A reambulação, nesse processo, em especial, se encontra inerte nesse cenário, com conceitos datando do século XIX e práticas rígidas. Sendo ela uma parte essencial do processo de construção do mapa, novas práticas devem ser discutidas, de modo a atualizá-la e torná-la mais eficiente, em um mundo onde a informação é cada vez mais dinâmica e rapidamente produzida e absorvida pelos indivíduos.

Destarte, este trabalho apresenta uma metodologia para a construção de uma base de dados voluntária de informação geoespacial utilizando plataformas móveis (smartphones e tablets). De forma a validar essa metodologia, é realizado um estudo de caso para coletar dados de postos de combustível e do seu entorno da cidade do Rio de Janeiro e inserir na base de dados do 
OpenStreetMap. Essa coleta foi idealizada devido à necessidade da Agência Nacional do Petróleo, Gás Natural e Biocombustíveis (ANP) de conhecer as instalações comerciais de combustível instalados em território nacional. A partir dessa experiência propõe-se a inserção do mapeamento colaborativo na produção cartográfica, mais especificamente na etapa da reambulação, de modo a promover uma atualização dinâmica das bases cartográficas e maior participação social nos processos de construção do território.

Para melhor compreensão, na seção 2 é efetuada uma revisão sobre informação geoespacial e colaboração; na seção 3 é apresentada a metodologia proposta para o estudo de caso; na seção 4 são apresentados os resultados obtidos, na seção 5 é apresentada uma reflexão sobre o processo de reambulação das Agências Nacionais de Mapeamento e, finalmente, na seção 6, as conclusões.

\section{Informação geoespacial e colaboração}

Atualmente a colaboração entre pessoas em prol de um bem coletivo se torna cada vez mais imprescindível. Nesse contexto, a informação geoespacial ganhou um papel social tornando-se um bem comum disponibilizada aos cidadãos, empresas e governo, como meio de organizar as informações e suas atividades no processo de tomada de decisões em diversos setores da sociedade (Rajabifard, 2008). Segundo Folger (2009), o governo federal dos Estados Unidos estima que cerca de $80 \%$ de todos os dados por eles administrados tem uma componente geográfica, e que esta informação é utilizada em todas as escalas da organização, desde Ministérios até as Secretarias.

A informação geoespacial se apresenta de diferentes tipos, formas e padrões e é mais flexível e dinâmica que outros tipos de dados. Desta forma, a informação geoespacial vem suplantando os antigos registros e introduzindo mais complexidade e maiores custos de aquisição e manutenção, visto que necessita de mecanismos mais avançados de gestão e controle.

De modo geral, esse trabalho visa promover uma reflexão para um maior aproveitamento das bases de dados colaborativas já existentes e que estão sendo constantemente atualizadas num ritmo muito superior àquele das bases oficiais. Todavia, a inclusão dos profissionais da reambulação no processo de integração e validação da informação geográfica voluntária é fundamental, pois apenas eles conhecem as características inerentes do serviço que prestam, e podem facilmente observar um registro mal coletado, ou então com informações prestadas que não condizem com a experiência acumulada ao longo de anos de trabalho.

Em questões onde os dados geográficos apresentam conflitos de nome ou localização, apenas o reambulador tem a competência de sanar esse problema, através da sua ida ao local duvidoso para realizar o cadastro da informação verdadeira. Ressalta-se ainda que no caso de demandas judiciais, apenas as informações coletadas pelos reambuladores são válidas para a resolução da questão que se apresenta.

O potencial que as informações geográficas voluntárias têm de dinamizar e atualizar as bases de dados é enorme, resolvendo assim, parte de grandes problemas enfrentados pelas Agências Nacionais de Mapeamentos, que são a atualização cartográfica e a dinâmica ultrapassada em que se encontra o mapeamento oficial. Diferente do que aconteceu com os outros processos cartográficos, quando a partir de meados da década de 80 , os processos tradicionais e os 
profissionais que os dominavam foram sendo substituídos e treinados paulatinamente para a assimilação dos novos sistemas, como por exemplo, na Geodésia, o uso do GNSS (Global Navigation Satellite System - Sistema Global de Navegação por Satélite) de alta precisão. A integração da reambulação colaborativa no mapeamento colaborativo traria uma maior importância e visibilidade para a área, além de assegurar uma constante atualização cartográfica e, consequentemente, à utilização de novas tecnologias e o desenvolvimento de métodos para garantir acurácia aos dados adquiridos com informação geográfica voluntária.

Do ponto de vista prático, apesar das Agências Nacionais de Mapeamentos terem responsabilidade de prestar serviços de qualidade e atualizados de acordo com a demanda da sociedade, o que se observa atualmente é que o uso do mapeamento oficial é mais concentrado na comunidade geoespacial. Por outro lado, o público em geral pouco utiliza os dados oficiais, preferindo utilizar serviços privados como o Google Maps ou o Here Maps disponíveis em smarthphones. Isso traz à tona uma disparidade entre a realidade rígida e tradicional que a agência está inserida, e aquela mais dinâmica e funcional que os usuários se encontram. Em função disso cabe destacar que as Agências Nacionais de Mapeamento das Américas, representadas no Comitê Permanente para a Infraestrutura de Dados Geoespaciais das Américas, (CP-Idea, 2012), apresentaram a proposta de inserir em seus projetos a incorporação da cartografia do Google Maps e do OpenStreetMaps (OSM) nos visualizadores dos Geoportais Nacionais, para tornar mais amigável e contextualizada a navegação e a implantação de conjuntos de dados temáticos, conforme apontado no diagnóstico sobre temas relevantes da gestão da informação geoespacial e desenvolvimento das Infraestruturas de Dados Espaciais nos países das Américas

Segundo Poore et al. (2012), o United States Geologic Survey (USGS) já vem discutindo em como realizar a transição para um modelo mais participativo, no caso, através do OSM. No Canadá, alguns órgãos oficiais há quatro décadas adotam uma postura de privatização das funções de mapeamento em suas jurisdições, passando a realizar um trabalho extensivo de controle de qualidade e de filtragem. Segundo Coleman. (2013), essa discussão ainda não foi concluída necessitando ainda de pesquisas. O controle que as organizações detinham sobre o mapeamento era muito grande e dividi-lo é ainda um ponto de incômodo para a maioria delas. Atualmente, a integração com os serviços voluntários, também não é diferente. Para muitas Agências Nacionais de Mapeamento oferecer controle e responsabilidade pode ser uma questão muito sensível.

\section{Metodologia}

Para o desenvolvimento do estudo de caso e maior controle dos resultados o trabalho foi efetuado em duas etapas. A primeira, de testes, realizada em uma área delimitada, para assimilação dos dados adquiridos e conhecimento da dimensão das contribuições. A segunda e última, mais livre, onde se disponibiliza o aplicativo para outros contribuintes, não havendo limite na área de estudo, conforme ilustrado na Figura 1.

Para o papel de contribuinte da informação geográfica voluntária da primeira etapa foram convidados os alunos do Departamento de Engenharia Cartográfica e da Faculdade de Geografia da Universidade do Estado do Rio de Janeiro. Para a segunda etapa, o projeto foi amplamente divulgado de modo a alcançar um maior número de usuários voluntários. 


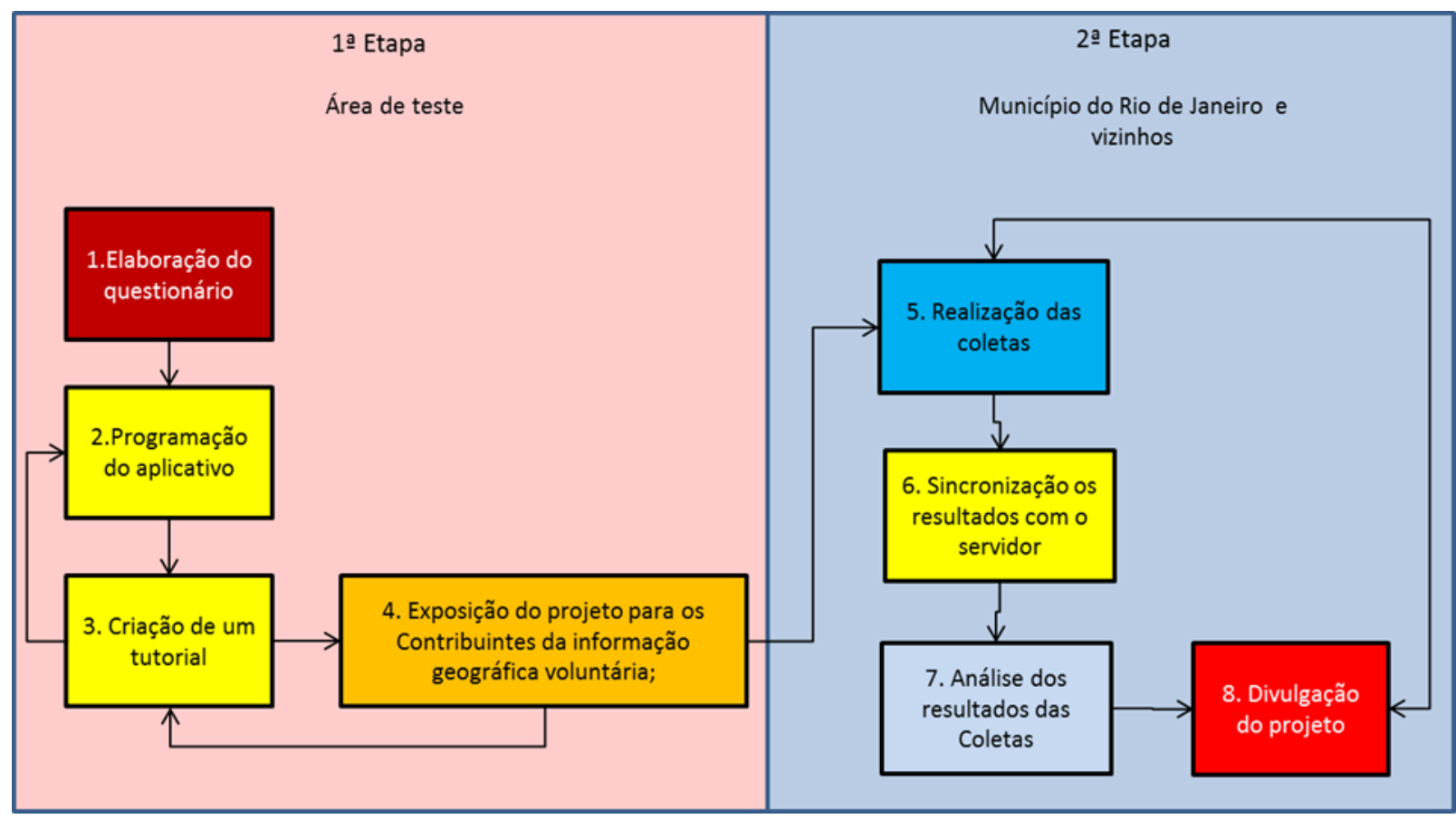

Figura 1: Etapas da metodologia.

\subsection{Elaboração do Questionário}

Tendo em vista os objetivos da Agência Nacional de Petróleo (ANP), determinou-se incialmente o conjunto de informações necessárias para a caracterização de um posto de combustível e os serviços oferecidos, a saber:

- Operador: empresa que realiza a operação do posto e é, portanto, a responsável legal por ele;

- Combustível: são quatro tipos mais comuns, sendo eles: gasolina, diesel, etanol e GNV (Gás Natural Veicular);

- Serviço de lavagem: podem ser de dois tipos, automático (quando é realizado por máquinas automatizadas) e manual (quando é realizada por funcionários do posto);

- Serviços mecânicos: são inúmeros, mas para este questionário determinaram-se os mais comuns e relevantes para a pesquisa, sendo eles: borracharia, calibração dos pneus, troca do extintor de incêndio, troca da palheta do vidro e troca do óleo do motor;

- Caixa eletrônico: equipamento que realiza transações bancárias e que é comumente encontrado em postos de combustível;

- Estacionamento;

- Loja de conveniência: estabelecimento comercial dependente do posto e que comercializa itens diversos; e

- Itens vendidos na loja de Conveniência - foram considerados itens relevantes à pesquisa: refrigerantes, bebidas alcoólicas, sorvetes e presentes em geral. A escolha da inclusão do item "bebidas alcoólicas" foi motivada pela Lei Estadual 


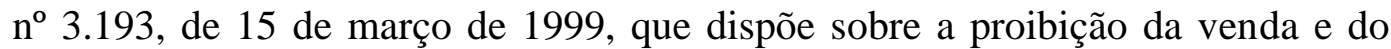
consumo de bebidas alcoólicas nas redes de postos de combustíveis no estado do Rio de Janeiro.

Diante deste conjunto de informações optou-se por um processo de reambulação através da aplicação de um questionário eletrônico disponível em plataformas móveis, com a possibilidade de aquisição de fotografia e das coordenadas da localização de um ponto no posto de combustível.

Quanto à elaboração do questionário, consideraram-se perguntas fechadas de interpretação fácil e direta, evitando-se ambiguidade nas respostas (Chagas, 2000, Gunther, 2003). Foi considerada ainda uma pergunta aberta de forma a permitir o usuário contribuir com comentários ou sugestões sobre o projeto, de modo a possibilitar uma participação mais inclusiva no projeto. $\mathrm{O}$ Quadro 1 descreve o questionário elaborado.

Quadro 1: Perguntas do questionário.

\begin{tabular}{|c|c|}
\hline Perguntas & Respostas Possiveis \\
\hline 1. Qual o operador do Posto? & Petrobras BR, Ipiranga, Shell/Esso, Ale ou Outros. \\
\hline $\begin{array}{l}\text { 2. Quais os tipos de combustível } \\
\text { vendidos? }\end{array}$ & Gasolina, Etanol, Diesel e GNV. \\
\hline 3. O posto oferece caixa eletrônico? & $\begin{array}{c}\text { Banco do Brasil, Caixa Econômica Federal, Itaú, } \\
\text { Bradesco, Santander, } 24 \text { Horas, Outros ou Não Possui. }\end{array}$ \\
\hline 4. O posto oferece lavagem? & $\begin{array}{l}\text { Sim, do tipo Manual; Sim, do tipo Automático; Não } \\
\text { Oferece. }\end{array}$ \\
\hline 5. O posto oferece serviços mecânicos? & $\begin{array}{l}\text { Borracheiro, Calibrador, Troca Extintor, Troca } \\
\text { Palheta do Vidro, Troca Óleo e Não Oferece. }\end{array}$ \\
\hline 6. O posto oferece estacionamento? & Sim ou Não. \\
\hline 7. O posto oferece loja de conveniência? & $\begin{array}{c}\text { Bob's, Subway, BR Mania, Mc Donald's, AM/PM, } \\
\text { Outros ou Não Oferece. }\end{array}$ \\
\hline $\begin{array}{l}\text { 8. Dos seguintes itens, algum é vendido no } \\
\text { posto? }\end{array}$ & $\begin{array}{c}\text { Refrigerantes, Bebidas Alcoólicas, Sorvetes, Presentes } \\
\text { ou Não Vende Nenhum dos Itens. }\end{array}$ \\
\hline $\begin{array}{l}\text { 9. Existe algum curso d'água próximo ao } \\
\text { posto? }\end{array}$ & Sim ou Não. \\
\hline 10. Comentários ou sugestões? & Resposta Livre. \\
\hline
\end{tabular}

\subsection{Delimitação da área de teste}

Para a delimitação da área de teste da primeira etapa foi realizada uma consulta espacial a base de dados do OSM de modo a localizar os estabelecimentos comerciais de postos de combustível na cidade do Rio de Janeiro. Dentre os critérios utilizados para a área de teste foi considerado a facilidade de locomoção na região, a boa infraestrutura de transporte e a relativa segurança encontrada nesses locais. Deste modo as Regiões Administrativas (RAs) de Jacarepaguá (XVI RA) e da Barra da Tijuca (XXIV RA) foram selecionadas uma vez que foram encontrados 34 e 31 postos, respectivamente, resultando assim em 65 postos na área de teste, conforme apresentado na Figura 2. 


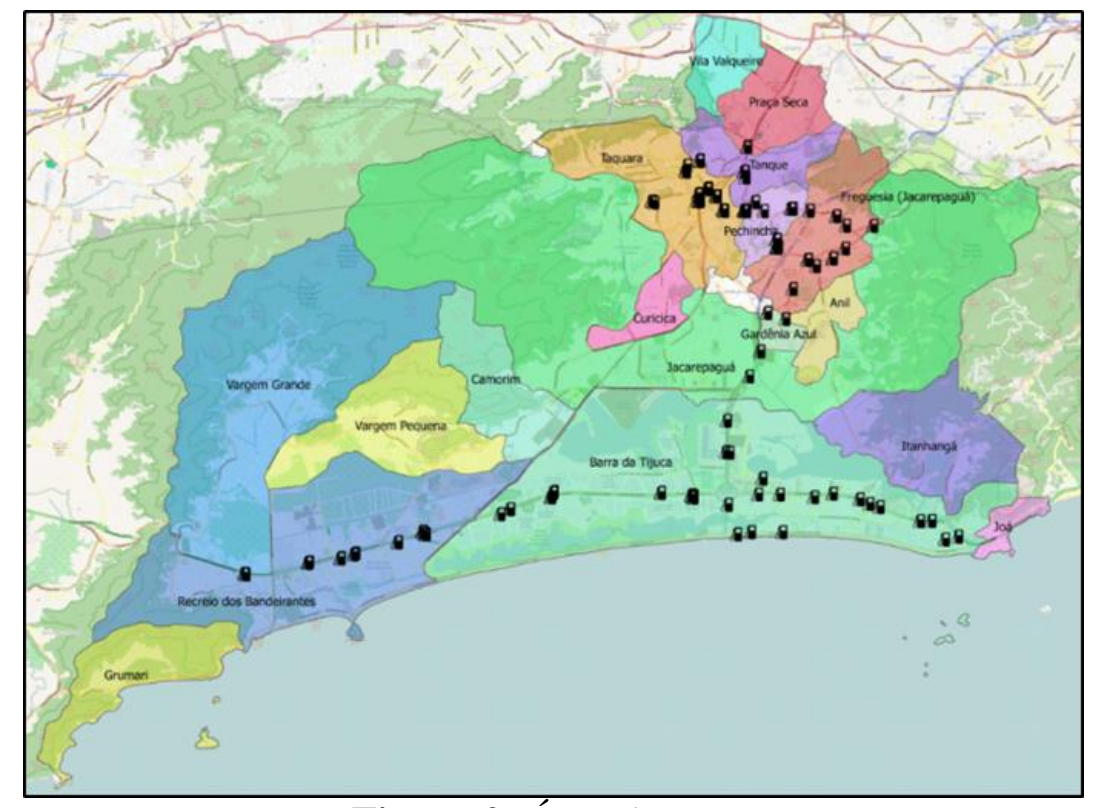

Figura 2: Área de teste.

\subsection{Programação do aplicativo PostoRJ}

Para a construção do questionário em um aplicação móvel foi utilizado o aplicativo EpiCollect. Trata-se de um projeto de código aberto, desenvolvido no Departamento de Epidemiologia de Doenças Infecciosas na Imperial College London, com fundos do The Wellcome Trust, que oferece um ambiente on line usando um sistema de point and click para construir ferramentas de coleta de dados em plataformas móveis (com sistema Android ou iOS) e enviá-los para qualquer servidor a qualquer momento em que haja conexão com a internet. $\mathrm{O}$ epiCollect oferece ainda um servidor padrão gratuito denominado Google AppEngine (Google Inc, 2015).

Os dados adquiridos são sincronizados e podem ser visualizados e manipulados no website do projeto correspondente ou no próprio aparelho responsável pelo registro. Em áreas remotas, onde as redes de telecomunicações são precárias ou inexistentes, o aplicativo consegue armazenar os dados coletados e cadastrar coordenadas do receptor GNSS do aparelho para, posteriormente, já com internet, envia-las ao servidor responsável.

Destarte, foi criado o aplicativo, nomeado de "PostosRJ", apresentado na Figura 3, que permite que os usuários respondam ao questionário e enviem as informações registradas para o servidor de dados. Neste trabalho foi utilizado o servidor padrão oferecido, o Google AppEngine (Aanensen et al., 2015). 


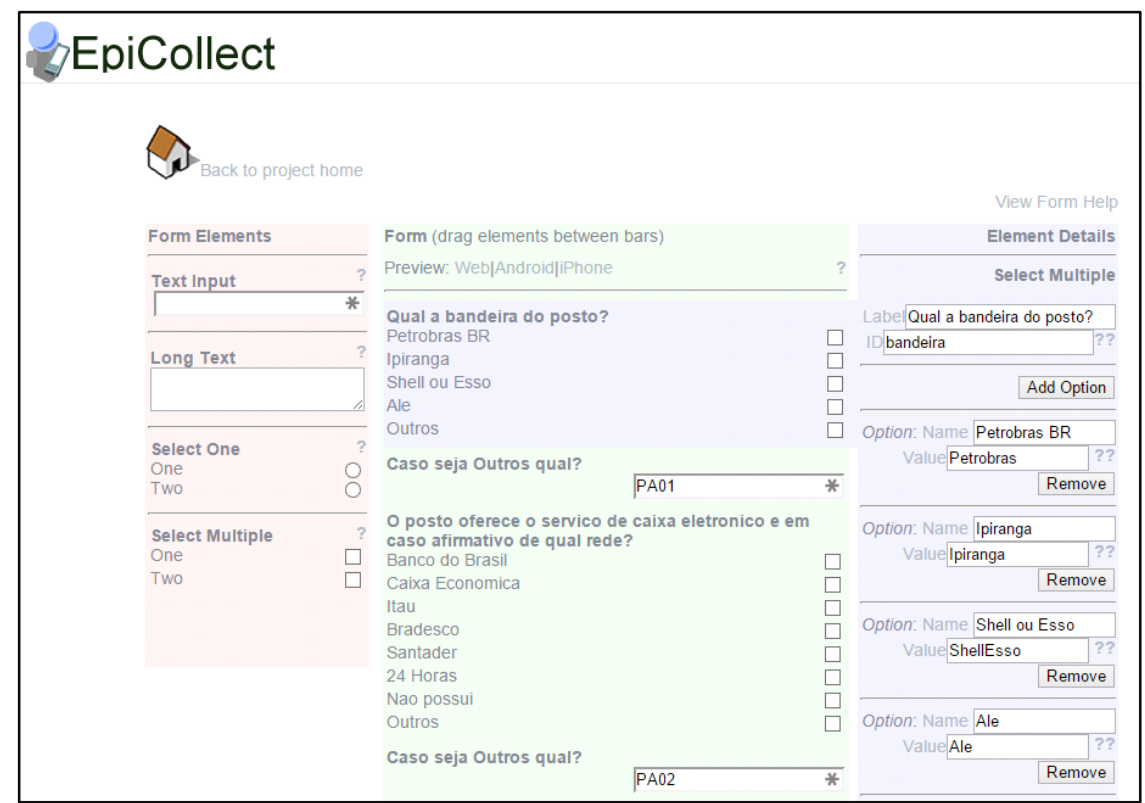

Figura 3: Questionário do aplicativo PostoRJ programável EpiCollect.

Um registro do posto de combustível, além de ter as respostas de todo questionário respondido, deve ter cadastrada uma fotografia do posto, as coordenadas geodésicas aferidas pelo receptor GNSS do aparelho celular.

\section{Resultado das coletas e carregamento dos dados no OSM}

A primeira etapa de coleta foi realizada entre 28 de novembro de 2014 e 18 de janeiro de 2015 , totalizando 114 registros e cerca de 80 postos diferentes coletados, representados na Figura 4.

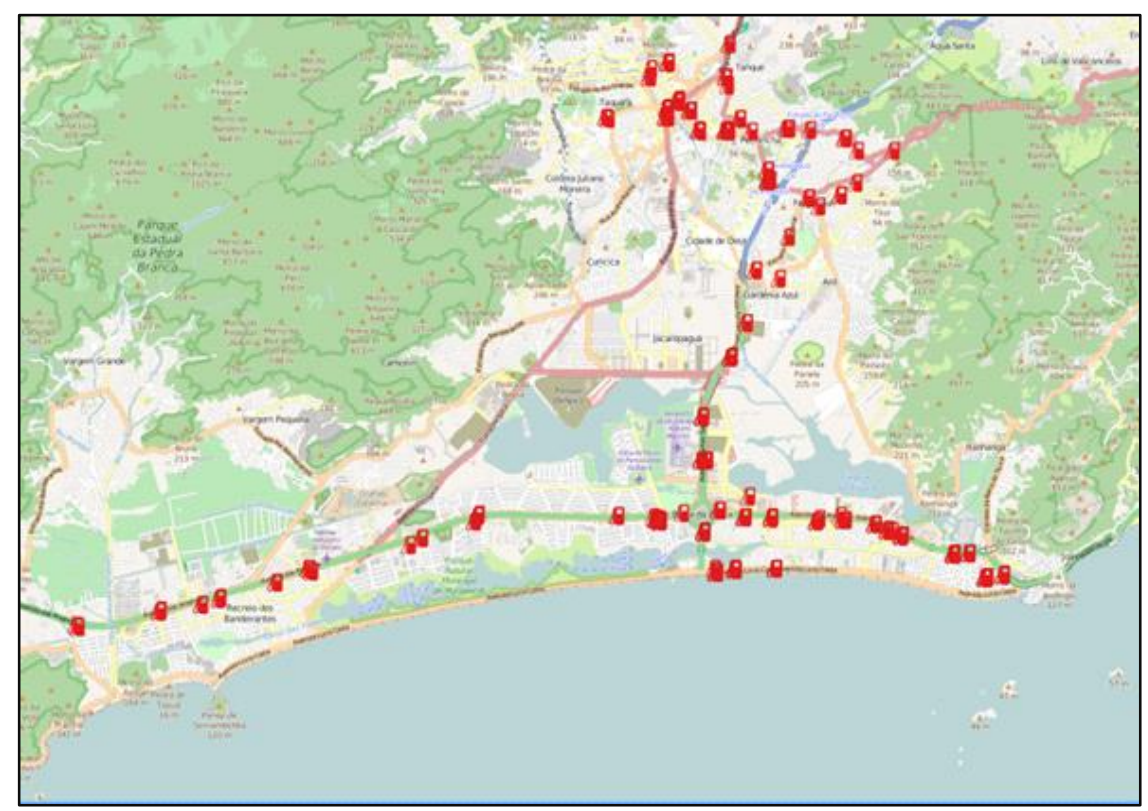

Figura 4: Registros coletados na primeira etapa - Coleta de Testes. 
Do total de 114 registros, apenas cinco estavam sem fotografias, nenhum sem coordenadas, apesar de 57 não apresentarem seus questionários completos. Observou-se na base de dados que informações sobre produtos vendidos, presença de caixa eletrônico e proximidade de curso d'água não foram respondidas de forma satisfatória, com apenas 18 registros dentre os 57 mencionados. A Tabela 1 reúne as características dos registros da etapa de testes, concluindo-se então que as coletas foram relativamente satisfatórias, com aproximadamente $65 \%$ dos registros válidos para o projeto.

Tabela 1: Características dos registros da Coleta de Teste.

\begin{tabular}{l|c|c}
\hline \multicolumn{1}{c|}{ Ocorrência } & Total & Proporção (\%) \\
\hline Registros sem Coordenadas & 0 & 0 \\
\hline Registros sem Fotografias & 5 & 4,39 \\
\hline Registros sem Bandeira do Posto & 36 & 31,58 \\
\hline Registros sem Caixa Eletrônico & 39 & 34,21 \\
\hline Registros sem Loja de Conveniência & 39 & 34,21 \\
\hline Registros sem Tipos de Combustível & 39 & 34,21 \\
\hline Registros sem Lavagem & 39 & 34,21 \\
\hline Registros sem Serviços Mecânicos & 39 & 34,21 \\
\hline Registros sem Estacionamento & 39 & 34,21 \\
\hline Registros sem Itens Vendidos & 39 & 34,21 \\
\hline Registros sem Curso d'água & 39 & 34,21 \\
\hline Total de Registros & 114 & 100 \\
\hline
\end{tabular}

A segunda etapa, incluindo novos voluntários, sem a definição de área, iniciou-se 05 de abril de 2015 e transcorreu até 02 de maio do mesmo ano. Nessa etapa, a única restrição para a coleta é que os postos deveriam estar no município do Rio de Janeiro ou nos seus municípios vizinhos.

Os registros ocorreram em diversas áreas do Grande Rio, sendo a maioria na Zona Norte da cidade (bairros da Vila da Penha, Irajá, Benfica e Bonsucesso), mas com ocorrências também no Centro, na Zona Sul (bairros do Catete, Flamengo e Laranjeiras) e nos municípios de Niterói e São Gonçalo (Figura 5).

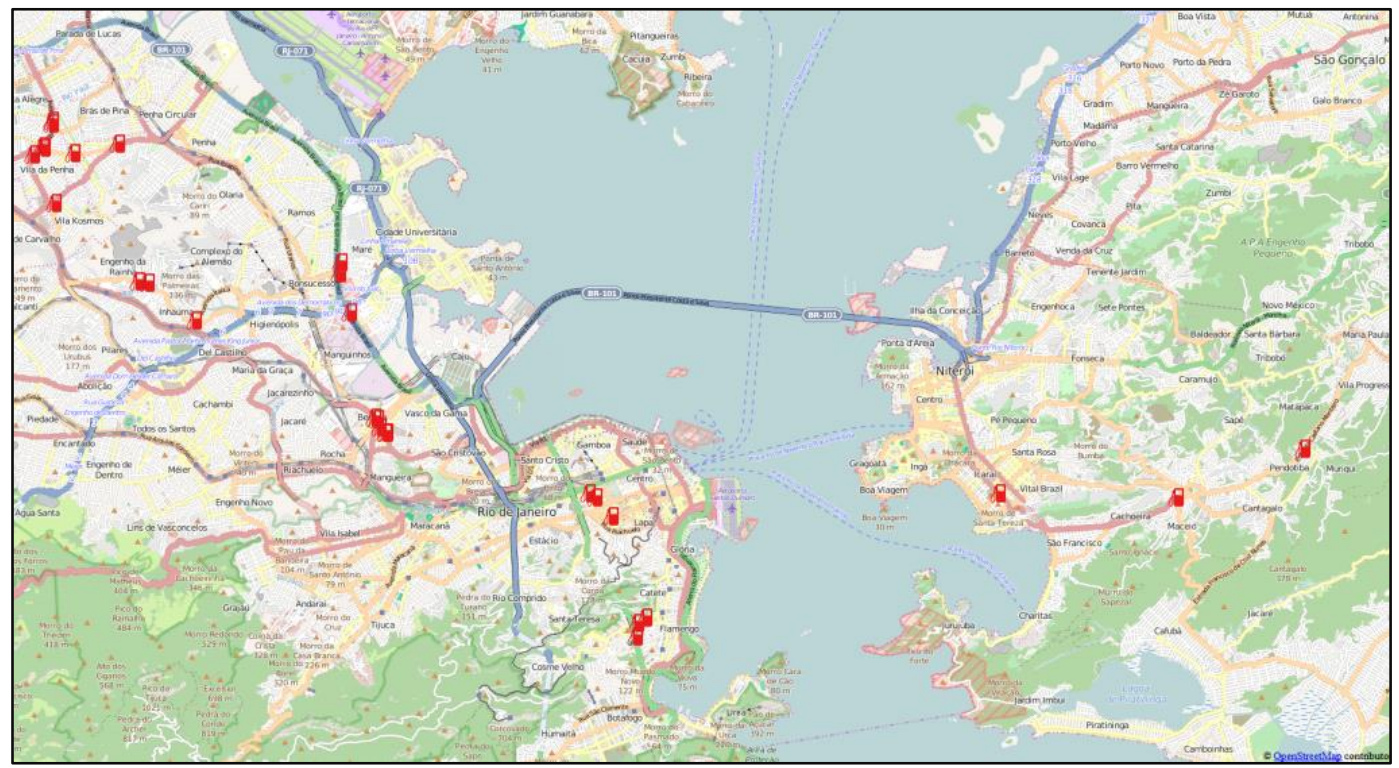

Figura 5: Registros coletados na segunda etapa de coleta livre. 
$\mathrm{Na}$ análise dos registros, verificou-se que apenas dois registros não tinham fotografias e nenhum sem coordenada. Em adição a isso, nenhum registro estava incompleto. A análise desta etapa é descrita na Tabela 2.

Tabela 2: Características dos registros da segunda etapa.

\begin{tabular}{l|c|c}
\hline \multicolumn{1}{c|}{ Ocorrência } & Total & Proporção (\%) \\
\hline Registros sem Coordenadas & 0 & 0 \\
\hline Registros sem Fotografias & 2 & 6,67 \\
\hline Registros sem Bandeira do Posto & 0 & 0 \\
\hline Registros sem Caixa Eletrônico & 0 & 0 \\
\hline Registros sem Loja de Conveniência & 0 & 0 \\
\hline Registros sem Tipos de Combustível & 0 & 0 \\
\hline Registros sem Lavagem & 0 & 0 \\
\hline Registros sem Serviços Mecânicos & 0 & 0 \\
\hline Registros sem Estacionamento & 0 & 0 \\
\hline Registros sem Itens Vendidos & 0 & 0 \\
\hline Registros sem Curso d'água & 0 & 0 \\
\hline Totalde Registros & 30 & 100 \\
\hline
\end{tabular}

Ao final de sete meses, foram coletados 144 registros, distribuídos pelo município do Rio de Janeiro, Niterói e São Gonçalo. O resultado final das coletas se encontra na Figura 6. Em pelo menos 36 registros $(25 \%)$ não houve nenhuma informação coletada, exceto coordenadas e fotografias. Em outros três registros, apenas a bandeira do posto foi informada. Em geral, aproximadamente $73 \%$ dos registros estão completos, o que demonstra que as coletas nessa etapa aberta foram efetivas, apesar do tempo de coleta ser menor do que na primeira etapa, e apresentam uma boa qualidade, conforme ilustrado na Figura 6 e na Tabela 3 as estatísticas descritiva dos dados.

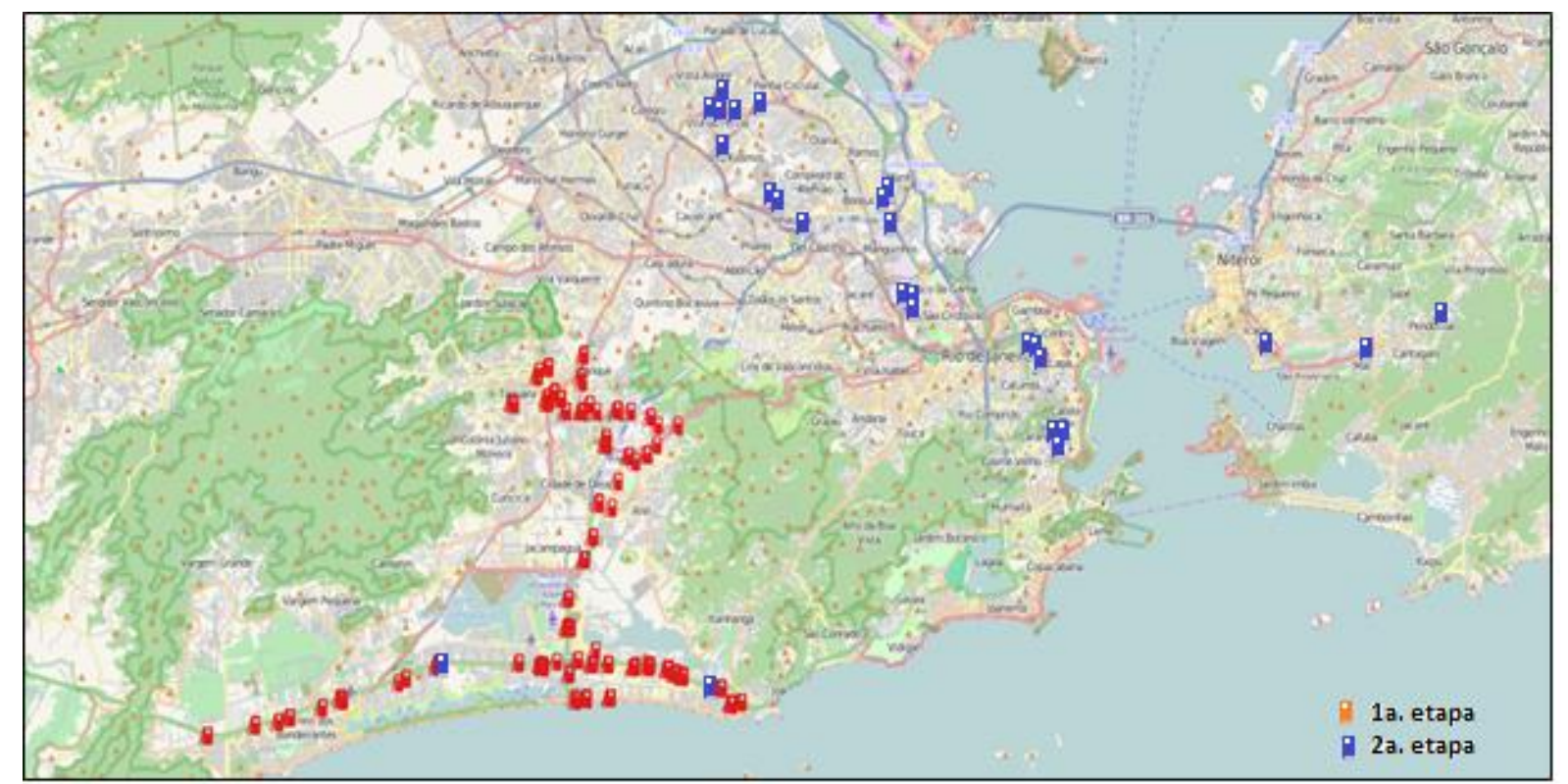

Figura 6: Total de registros coletados nas duas etapas.

A primeira etapa foi controlada e direcionada a um público-alvo, alunos de graduação em engenharia cartográfica e geografia. A segunda etapa, aberta a comunidade, teve um período menor de observação dos dados e consequentemente uma participação menor devido ao tempo para a realização deste estudo de caso no âmbito do projeto. Observa-se, portanto, quando o 
evento é aberto à comunidade deve-se haver uma massiva divulgação do projeto e um estímulo à participação voluntária.

Tabela 3: Resultado Final da Coleta.

\begin{tabular}{l|c|c}
\hline \multicolumn{1}{c|}{ Ocorrência } & Total & Proporção (\%) \\
\hline Registros sem Coordenadas & 0 & 0 \\
\hline Registros sem Fotografias & 7 & 4,86 \\
\hline Registros sem Bandeira do Posto & 36 & 25 \\
\hline Registros sem Caixa Eletrônico & 39 & 27,08 \\
\hline Registros sem Loja de Conveniência & 39 & 27,08 \\
\hline Registros sem Tipos de Combustível & 39 & 27,08 \\
\hline Registros sem Lavagem & 39 & 27,08 \\
\hline Registros sem Serviços Mecânicos & 39 & 27,08 \\
\hline Registros sem Estacionamento & 39 & 27,08 \\
\hline Registros sem Itens Vendidos & 39 & 27,08 \\
\hline Registros sem Curso d'água & 39 & 27,08 \\
\hline Total de Registros & 144 & 100 \\
\hline
\end{tabular}

Analisando-se esses dados, em pelo menos 36 registros (25\%) não houve nenhuma informação coletada exceto coordenadas e fotografias, conforme ilustrado no Gráfico 1. Em outros três registros apenas a bandeira do posto foi informada. Em geral, aproximadamente $73 \%$ dos registros estão completos, o que demonstra que as coletas tiveram um bom resultado e que os dados coletados tem uma boa qualidade.

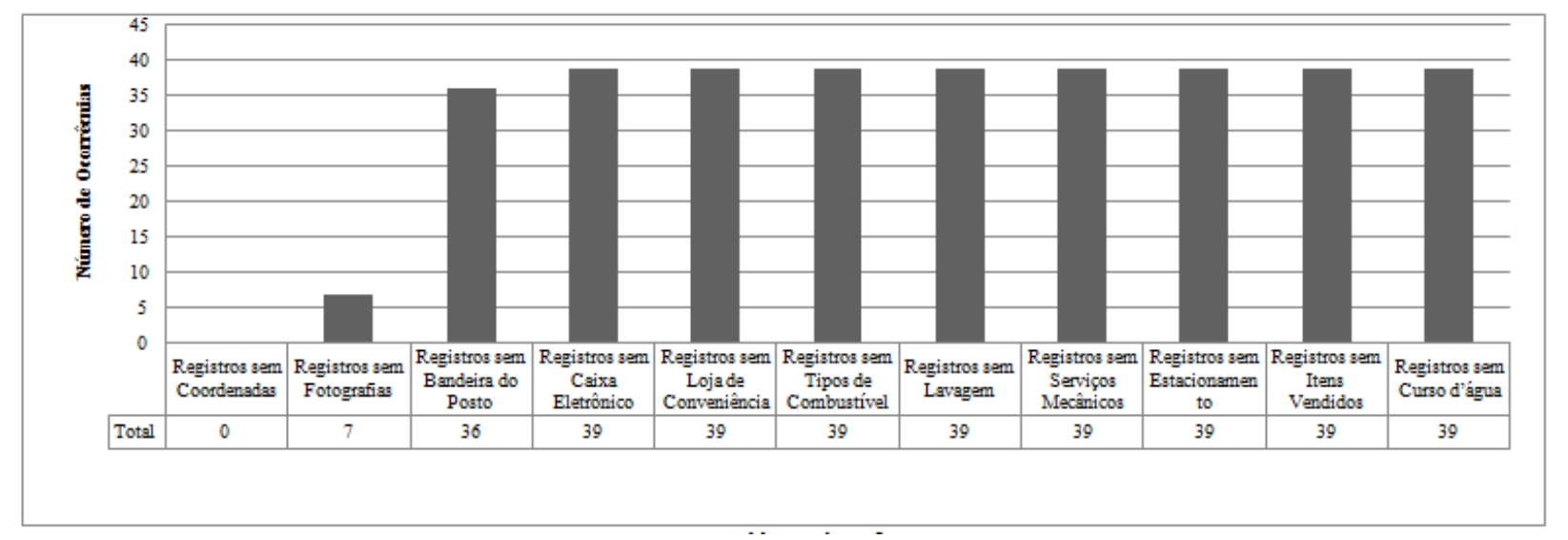

Gráfico 1: Análise de data missing.

A adaptação dos registros coletados para o padrão OSM requereu uma adequação das etiquetas para o padrão utilizado pelo OSM. As etiquetas no OSM podem ser criadas, editadas ou utilizadas por outros usuários. Isso, a princípio, é interessante para o propósito do mapa aberto e colaborativo. Entretanto, no que concerne aos padrões de dados utilizados pelas Agências Nacionais de Mapeamentos, o padrão OSM se torna difuso e pouco rígido, o que deixa de ser atrativo para essas instituições. Um exemplo é a discussão sobre a integração entre o USGS, o OSM e o padrão de dados a ser adotado (Bearden, 2007).

Neste trabalho, estabeleceu-se um padrão de etiquetas específicas para representação de cada aspecto do dado coletado, que é apresentado no Quadro 2. Ressalta-se que os nomes das etiquetas foram definidos em língua inglesa apenas para propósito de adequação ao sistema do OSM, cuja língua original é o inglês. Outra importante observação é a de que as etiquetas Amenity, Brand, Name, Operator são obrigatórias para qualquer registro. A etiqueta Shop e Shop_name se tornam obrigatórias quando existir informação sobre loja de conveniência. 
Quadro 2: Padrão de etiquetas utilizadas no OSM para este trabalho.

\begin{tabular}{|c|c|}
\hline Etiqueta & Possíveis Respostas \\
\hline Amenity & Fuel (combustível) \\
\hline Brand & Petrobras, Ipiranga, Shell, Esso ou Ale. \\
\hline Name & Marca antecedido da palavra "Posto" (ex. Posto Ipiranga). \\
\hline Operator & Petrobras, Ipiranga, Shell, Esso ou Ale. \\
\hline Atm & Banco do Brasil, Caixa Econômica, Itaú, Bradesco, Santander e 24 Horas. \\
\hline Shop & convenience (conveniência) \\
\hline Shop_name & Bob's, Subway, BR Mania, Mc Donald's, AM/PM ou Outros. \\
\hline Type_of fuel & Gasoline, ethanol, gnv e diesel. \\
\hline Service & $\begin{array}{c}\text { Tyres (calibrador/borracheiro), Fire extinguisher (troca de exintor), oil (troca } \\
\text { de óleo), glass reed (palheta de vidro), manual washing (lavagem manual) e } \\
\text { auto washing (lavagem automática). }\end{array}$ \\
\hline Parking & Surface (superfície/descoberto) ou undergound (subterrâneo). \\
\hline $\begin{array}{l}\text { Shop_items (itens } \\
\text { vendidos) }\end{array}$ & $\begin{array}{c}\text { Soft drinks (refrigerantes), alcoholics (bebida alcoólica), gifts (presentes) e ice } \\
\text { creams (sorvetes). }\end{array}$ \\
\hline
\end{tabular}

Todos os registros foram então incluídos na base do OSM seguindo o padrão estabelecido, atingindo-se assim, o objetivo proposto.

\section{Reflexão sobre o processo de reambulação contemporâneo}

Este trabalho teve por finalidade principal propor uma metodologia para atualização para a etapa de reambulação do mapeamento oficial. A partir deste estudo de caso aplicado a postos de combustível e da análise sobre a qualidade das informações voluntárias, são propostos cinco pontos para a sua implantação nas atividades de reambulação dos órgãos oficiais, conforme apresentado na Figura 7, de modo a incorporar novas tecnologias para o mapeamento colaborativo. Entretanto, ressalta-se que esses pontos estão longe de serem simples ou de serem respostas a questões que se apresentam, a saber:

1. Desenvolvimento de um aplicativo oficial para a coleta de informações pela população e um cadastro de usuários voluntários.

- O aplicativo oficial além de proporcionar confiança aos usuários estabelece uma relação com a sociedade. Entretanto, se faz necessário a criação de um cadastro de usuário, podendo esse ser feito através das redes sociais existentes, como o Facebook. Desse modo, os usuários podem ser recompensados, por exemplo, através da publicação de seus nomes nas listas de contribuintes do órgão oficial e posteriormente possa ser criado um sistema de recompensa ou gamificação.

2. Divulgação do aplicativo e do serviço para a população, visando principalmente às redes sociais e outras mídias digitais.

- O público-alvo é amplo e muito heterogêneo, entretanto deve-se priorizar a faixa etária de 15 a 30 anos, tendo em vista a sua integração com as novas tecnologias e uma maior participação dessa faixa etária em projetos dessa natureza. 


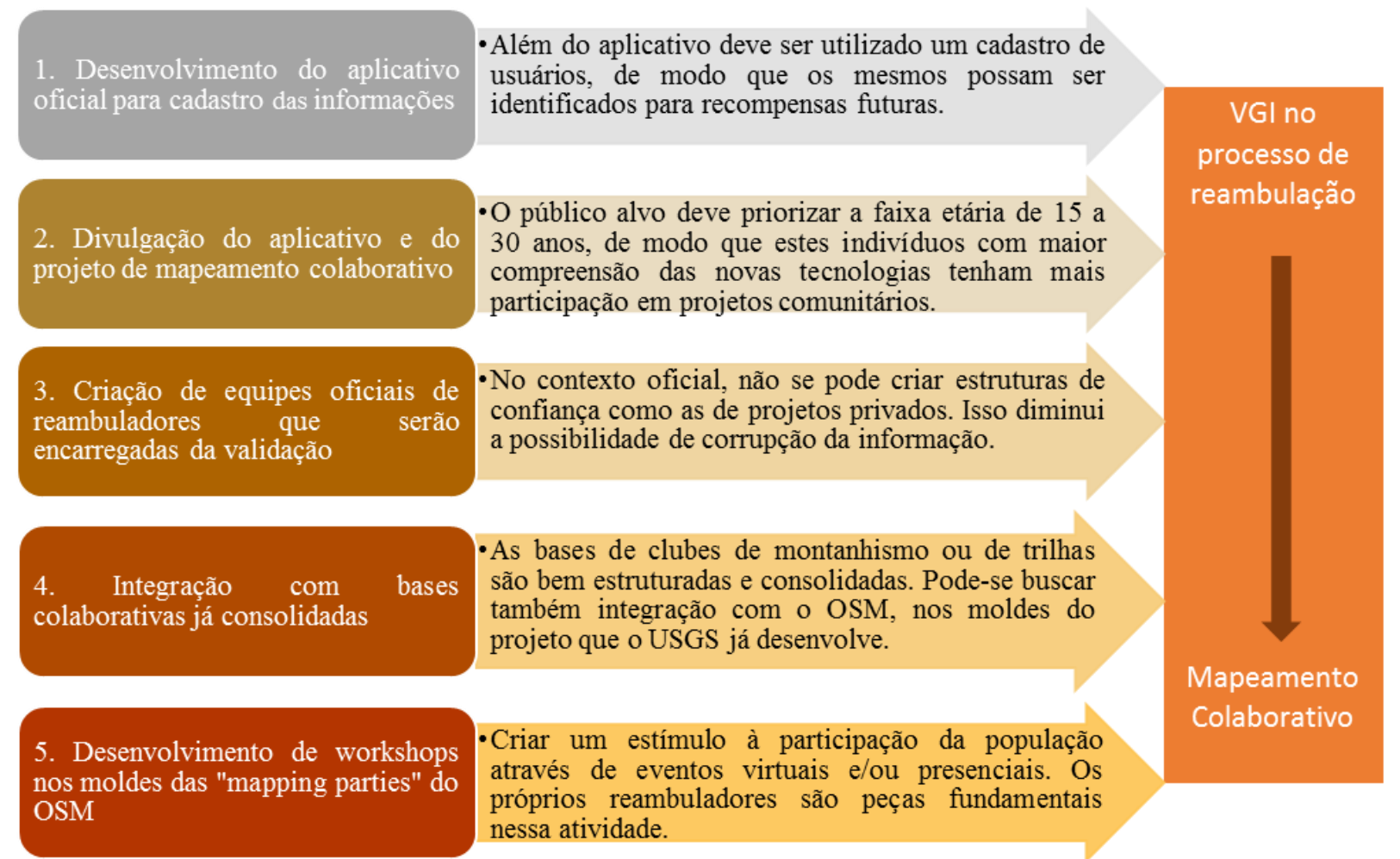

Figura 7: Implantação da informação geográfica voluntaria à reambulação.

3. Criação de equipes de reambuladores nos órgãos oficiais que serão encarregadas de validar todas as informações que chegarem.

- Este ponto deve atribuir um alto grau de confiabilidade que a informação poderá ter no futuro. Isso também diminui a possibilidade de corrupção da informação, o que já aconteceu com o serviço do Google Map Maker (Google, 2014).

4. Integração com bases já consolidadas, como as de clubes de montanhismo ou de trilhas, e outras organizações que possuam bases voluntárias que podem ser absorvidas no mapeamento oficial.

5. A base de dados construída por estes grupos, em geral, reúne nomes de acidentes geográficos (montanhas e picos), que constitui em informação essencial a ser considerada para os mapas oficiais (Santos, 2008). Por exemplo, o modelo de integração adotado pelo USGS em relação ao OpenStreetMap (OSM), que vem adaptando as bases oficiais para recebimento das informações deste último para posterior adição ao mapa nacional dos Estados Unidos (Wolf et al., 2011). Desenvolvimento de workshop nos moldes das mapping parties ou de eventos de missing maps do OSM para assistência áreas carentes ou de emergência.

- Os workshops presenciais e/ou virtuais visam estabelecer uma maior interação na comunidade e promover o conhecimento do espaço geográfico pela mesma.

- No caso das agências oficiais, esses encontros podem ser promovidos para estimular a coleta em determinada região onde se faz necessário um maior volume de informações.

- A participação dos próprios reambuladores e de outros profissionais técnicos dos órgãos oficiais pode aproximar a população do processo de construção do território e desenvolvimento de uma nova cultura de colaboração com as Agências Nacionais de Mapeamento.

Nesse contexto, é importante ressaltar que as coletas voluntárias não são comparáveis ou competem com as coletas dos profissionais de reambulação. O trabalho voluntário é livre, mas 
estimulado por uma infraestrutura profissional que o ajuda a desenvolver habilidades tradicionalmente técnicas e contribuir para uma melhora da qualidade da base de dados oficial.

Entretanto, para as Agências Nacionais de Mapeamento estarem inseridas no ambiente do VGI precisam aceitar que a comunidade, ao se formar, impõe suas próprias regras, têm seus próprios preceitos e papéis e não aceitaria nenhum tipo de ação autoritária por parte das agências. Deve-se também atentar para o fato de que o dado voluntário está em permanente atualização, de modo que, ao se entregar um produto proveniente dele à sociedade, este estará sujeito a constantes atualizações. Segundo Coleman et al. (2009), algumas agências percebem isso como sendo um risco a sua reputação e a legitimidade do trabalho que fazem, o que se torna em um dos maiores obstáculos para a integração da informação geográfica voluntária a base de dados oficial.

\section{Conclusões}

Em um país com dimensões continentais como o Brasil, o processo de mapeamento é uma atividade fundamental para conhecimento do território de forma abrangente e também na afirmação de uma identidade nacional.

$\mathrm{Na}$ sociedade contemporânea, as Agências Nacionais de Mapeamento (ANM) produzem cartografia para uma sociedade onde as crianças estão inseridas mais cedo no processo de integração do ser humano com a tecnologia. Nesse contexto as ANM tem sua produção competindo com os sistemas colaborativos de mapeamento oferecidos a sociedade em diversas mídias. Este processo é ocasionado pelo aspecto social que a cartografia tem e pela evolução tecnológica disponível a sociedade. Isso vem possibilitando que as informações geoespaciais sejam populares e cada vez mais utilizadas pela sociedade. Como exemplo, tem-se atualmente os projetos como o OpenStreetMap e WikiMapia, que em poucos anos, já possuem bases comparáveis às oficiais, que levaram décadas para chegarem ao estado atual

Todavia, as Agências Nacionais, em especial, no Brasil, o IBGE e a Diretoria de Serviço Geográfico (DSG) do Exército Brasileiro, continuam empregando em seu processo de produção cartográfica práticas rígidas cujo custo de produção é alto em detrimento de outras questões nacionais.

Dentre os processos cartográficos, a reambulação, se encontra inerte nesse cenário, necessitando de reformulação em suas práticas. Trata-se de uma etapa importante do processo de construção do mapa, e dessa forma novas práticas devem ser discutidas, de modo a trazê-la para o século XXI, onde a informação é cada vez mais dinâmica e rapidamente produzida e absorvida pelos indivíduos. O estudo de caso aplicado aos postos de combustíveis no município do Rio de Janeiro mostrou que são viáveis projetos dessa natureza para a automação de parte do processo de reambulação. Entretanto é necessário criar meios para obter a colaboração na aquisição da informação geográfica voluntária.

A inserção do conceito de informação geográfica voluntária e a integração desta às bases de dados oficiais podem trazer mais dinamismo e flexibilidade aos processos, além de integrar a

Bol. Ciênc. Geod., sec. Artigos, Curitiba, v. 22, no4, p.613-629, out - dez, 2016. 
sociedade como participante na fundamental tarefa de mapeamento. Destarte, para as agências oficiais desenvolverem-se nesse sentido precisam primeiro perceber que além da eficiência e qualidade de seus produtos, existe a necessidade de reformulação de seus métodos e procedimentos para a aquisição de informações geoespaciais, tornando-os mais abertos e integrados à sociedade. Para isto, as mídias sociais, como Facebook, Twitter e Foursquare, onde milhões de usuários a cada segundo compartilham suas informações de posição, aspectos culturais e físicos dos locais em que se encontram, etc, devem ser consideradas, mineradas e filtradas para sua inserção na base de dados oficial.

\section{REFERÊNCIAS BIBLIOGRÁFICAS}

Aanensen, D. M.; Huntley, D. M.; Feil, E. J.; al-Own, F.; Spratt, B. G. EpiCollect: Linking Smartphones to Web Applications for Epidemiology, Ecology and Community Data Collection. PLoS ONE, 2009. Disponível em http://journals.plos.org/plosone/article?id=10.1371/ journal.pone.0006968. Acessado em janeiro 2016.

Anand, S.; Jeremy, M.Y; Jiang, W.; Du, H.; Hart, G.; Jackson, M. When worlds collide: combining Ordnance Survey and Open Street Map data. In: Proceedings of the AGI Geo Community Conference, Stratford-upon-Avon, United Kingdom, 2010. Disponível em http://www.agi.org.uk/storage/geocommunity/papers/SucithAnand.pdf. Acessado em janeiro 2016.

Bearden, M. The National Map Corps - The USGS Volunteer Geographic Information Program Position Paper, 2007. Disponível em http://www.ncgia.ucsb.edu/projects/vgi/docs/position/ Bearden_paper.pdf. Acessado em Julho de 2015:

Budhathoki, N. R., Bruce, B., Nedovic-Bucic, Z. Reconceptualizing the role of the user of spatial data infrastructure. GeoJournal, v. 72, n. 3-4, p. 149-160, 2008.

Chagas, A. T. R. O Questionário na Pesquisa Científica - Administração on-line, v. 1, n. 1, 2000.

Cp Idea - Comité Permanente para la Infraestructura de Datos Geoespaciales de las Américas. Diagnóstico sobre temas relevantes de la gestión de información geoespacial y desarrollo de las Infraestructuras de Datos Espaciales (IDE) en los países de las Américas: 2009-1013. Disponível

em

http://papersmart.unmeetings.org/media2/2837954/e_conf_103_13_relatorio_final__diagnos tico_2011.pdf. Acessado em dezembro de 2015

Camboim, S. P.; Sluter, C. R.; Mendonça, A.; Jorge, M. T. E.. Mapeamento sistemático: a base para as Infraestruturas Nacionais de Dados Espaciais. In: Anais do II Simpósio Brasileiro de Ciências Geodésicas e Tecnologias da Geoinformação. Recife - PE, 2008

Coleman, D. J. Georgiadou Y., Labonte J. Volunteered Geographic Information: The Nature and Motivation of Produsers. International Journal of Spatial Data Infrastructure Research, v. 4, p. 332-358, 2009.

Coleman, D. J., 2013. Potential Contributions and Challenges of VGI for Conventional Topographic Base-Mapping Programs. In: Crowdsourcing Geographic Knowledge. Ed. Springer, p. 245-263, 2013

Dobson, M. W. VGI as Compilation Tool for Navigation Map Databases, In: Crowdsourcing Geographic Knowledge, Ed. Springer, p. 307-327, 2013. 
Folger, P. Geospatial Information and Geographic Information Systems (GIS): Current Issues and Future Challenges. Paper presented at Congressional Research Service, 2009.

Girres, J.-F., Touya, G. Quality assessment of the French OpenStreetMap dataset. Transactions in GIS 14, p. 435-459, 2010

GFDRR - Global Facility for Disaster Reduction and Recovery. Open Data for Resilience Initiative: Field Guide, 138 p., 2014.

Goodchild, M. Citizens as Voluntary Sensors: Spatial Data Infrastructure in the World of Web 2.0. International Journal of Spatial Data Infrastructure Research, v. 2, p. 24-32, 2007.

Google Inc. (2014). Termo de Serviço para o Google Map Maker. Disponível em https://www.google.com/mapmaker/intl/pt_ALL/mapfiles/s/terms_mapmaker.html. Acessado em Julho de 2015:

Google Inc.(2015). Website Informativo desenvolvido pelo Google Map Maker. Disponível em https://support.google.com/mapmaker?hl=en\#topic=3180752. Acessado em Julho de 2015:

Gunther, Hartmut. Como elaborar um questionário. Série Planejamento de Pesquisa nas Ciências Sociais, n. 1. Laboratório de Psicologia ambiental. Instituto de Psicologia. Universidade de Brasília, 2003

Haklay, M. How good is volunteered geographical information? A comparative study of OpenStreetMap and Ordnance Survey datasets. 2010. Environment and planning. B, Planning \& design 37, 682, 2010. Disponível em http://kfrichter.org/crowdsourcing-material/day1 /haklay10.pdf. Acessado em Julho de 2015:

Haklay, M.; Weber, Patrick. OpenStreetMap: User-Generated Street Maps. Pervasive computing published by the IEEE CS, n. 153, 2008.

Heipke, C. Crowdsourcing Geospatial Data. International Society of Photogrammetry and Remote Sensing. Journal of Photogrammetry and Remote Sensing, n. 65, p. 550 - 557, 2010.

Mooney, P., Morley, J. Crowdsourcing in National Mapping. In: Proceedings of the Euro SDR Workshop, Vienna, Euro SDR Official, Publication, no. 64. 2014. Disponível em http://www.eurosdr.net/sites/default/files/uploaded_files/eurosdr_no64_d.pdf. Acessado em Maio de 2015:

Poore, B. S., Wolf, E. B., Matthews, G. D., Korris, E. M., Walter, J. L. Structures Data Collection for The National Map using Volunteered Geographic Information. United States Department of the Interior/ United States Geological Survey. 2012

Rajabifard, A. A Spatial Data Infrastructure for a Spatially Enabled Government and Society. A multi-View Framework to Assess Spatial Data Infrastructures. 2008.

Santos, C. J. B. Geonímia do Brasil: A Padronização dos Nomes Geográficos num Estudo de Caso dos Municípios Fluminenses. Tese de Doutorado da Faculdade de Geografia da Universidade Federal do Rio de Janeiro, 2008.

Recebido em novembro de 2015.

Aceito em fevereiro de 2016. 